\title{
Proportion of vulvar premalignant and malignant lesions in overall vulvar specimens in Thailand
}

\author{
Ananya Trongpisutsak, Patou Tantbirojn*, Ruangsak Lertkhachonsuk
}

\begin{abstract}
Background: Vulvar lesion is one of the common gynecologic problems.

Objective: To assess the proportion of vulvar premalignant and malignant lesions in overall vulvar specimens and to evaluate the clinicopathologic features of each vulvar lesion in King Chulalongkorn Memorial Hospital (KCMH).

Methods: Pathological microscopic slides and medical records of the patients who underwent vulvar-related operations between January 1, 2002 and December 31, 2015 were reviewed. Patients' clinical characteristics and pathologic features were evaluated and analyzed.

Results: A total number of 700 patients were included. The proportion of malignant and premalignant lesions in overall vulvar specimens were $16.3 \%$ and $8.4 \%$, respectively. Squamous cell carcinoma was the most common malignant vulvar lesion (48.2\%), whereas vulvar intraepithelial neoplasia 1 (VIN1) (33.9\%) was the most common lesion in the premalignant group. On multivariate analysis, four clinical factors were significantly associated with malignancy risk: increased parity (odds ratio [OR] 1.19, $P=0.010$ ), large tumor size (OR 2.00, $P<0.001$ ), lesion at clitoris (OR 16.67, $P=0.002$ ), and erythematous lesion (OR 2.41, $P=0.026)$.

Conclusions: The proportion of malignant and premalignant lesions in overall vulvar specimens was $24.7 \%$ in $\mathrm{KCMH}$. Increased parity, large tumor size, clitoris-located lesion, and erythematous lesion were associated with increasing malignancy risk.
\end{abstract}

Keywords: carcinoma, squamous cell; vulvar diseases; vulvar neoplasms

Vulvar lesion is one of the common gynecologic problems. It can be categorized into three groups, which are benign, premalignant, and malignant lesion. The general appearance is varying in size, character, and color. The squamous cell carcinoma mostly present as a mass or chronic ulcer, which is frequently assumed to be a benign lesion [1]. The vulvar intraepithelial neoplasia (VIN) could be presented as maculopapular lesion that has many different colors such as white, pink, red, or even dark brown. The malignant melanoma is typically a hyperpigmented lesion but can also be seen as a hypopigmented lesion [2]. Therefore, it is difficult to diagnose the lesion without the pathological result.

Vulvar cancer constitutes $3 \%-8 \%$ of all female genital malignancies [3, 4]. About 27,000 women worldwide are

*Correspondence to: Patou Tantbirojn, Department of Obstetrics and Gynecology, Faculty of Medicine, Chulalongkorn University, Bangkok 10330, Thailand, e-mail: patrue.t@chula.ac.th

Department of Obstetrics and Gynecology, Faculty of Medicine, Chulalongkorn University, Bangkok 10330, Thailand

¿ Open Access. $\odot 2018$ Ananya Trongpisutsak et al., published by Sciendo. (c) Br-Nc-ND This work is licensed under the Creative Commons Attribution NonCommercial-NoDerivatives 4.0 License. 
diagnosed with vulvar cancer each year [3]. It has been estimated that vulvar cancer occurs in 2.5 per 100,000 womenyears in developed countries. However, it is two to three times more frequent in the developing countries. An increasing incidence of VIN and vulvar cancer has been reported in the past decade. The possible explanation including increasing rate of human papilloma virus (HPV) infection due to an early onset of intercourse and a higher participation in early diagnostic measurement [4]. The incidence of vulvar cancer begins to increase quickly after the age of 50 years [5]. VIN and vulvar cancers need more concerns and may become an important problem in the future with regard to the trend of increasing aging population.

There are very limited data of pathological diagnosis and clinicopathologic features of vulvar lesion in Thailand. Only three reports have been published, and they focused only on the cancerous lesion [6-8]. The primary objective of this study was to assess the proportion of vulvar premalignant and malignant lesions in overall vulvar specimens at King Chulalongkorn Memorial Hospital (KCMH), a tertiary-care hospital and medical school, during a period of 14 years. Secondary objective was to evaluate the clinicopathologic features of each vulvar lesion.

\section{Materials and methods}

Retrospective descriptive study was conducted after approval from the Institutional Review Board, Faculty of Medicine, Chulalongkorn University (certificate of approval No. 305/2016). Pathologic reports of vulvar specimens from all patients who underwent vulvar-related operations between January 1, 2002 and December 31, 2015 at KCMH were retrieved from the database of Division of Gynecologic Pathology. Microscopic slides of all cases were reviewed by experienced gynecologic pathologist to confirm the diagnosis. Patients' clinical characteristics including age, menopausal status, parity, lesion size, and lesion's color were collected from the medical record. Cases with unavailable formalin-fixed paraffin blocks or medical records were excluded from the study.

Statistical analysis was performed using SPSS software version 17 (SPSS Inc., Chicago, IL, USA). The patients' clinical characteristics and pathological data were compared by descriptive statistics including crude number, frequency, mean, and standard deviation. Pearson's chi-squared test and unpaired $T$ test were used to determine whether there is a statistical difference in categorical and continuous data, respectively. The univariate and multivariate logistic regression analysis were used to access for the odd ratio that the lesion would be premalignant or malignant lesion. All statistical tests were two sided, and $P<0.05$ was considered significant.

\section{Results}

A total number of 700 patients were included in this study. About 114 patients were malignant (16.3\%), 59 patients were premalignant $(8.4 \%)$, and 527 patients were benign (75.3\%). The pathological diagnosis distribution is shown in Table 1. Squamous cell carcinoma was the most common malignant vulvar lesion and accounted for nearly half of the malignant cases. The second and third most common malignant vulvar lesion is malignant melanoma and adenocarcinoma, respectively. In premalignant lesion, VIN1 and VIN3 were each diagnosed in approximately one-third of cases. Fibroepithelial polyp was the most common benign lesion $(23.9 \%)$.

Demographic data are listed in Table 2. Age of the patients ranged from 13 to 93 years with the mean age of 47.7 years. Mean age of the benign group was significantly lower than the premalignant and malignant groups. Almost $70 \%$ of the included populations were multiparous. Majority of the patient in the benign group were premenopause $(65.7 \%)$, while in

Table 1. Diagnosis of vulvar lesion in number and percentage

\begin{tabular}{|c|c|c|c|}
\hline \multicolumn{2}{|l|}{ Malignant $(n=114)$} & \multicolumn{2}{|l|}{ Benign $(n=527)$} \\
\hline $\begin{array}{l}\text { Squamous cell } \\
\text { carcinoma }\end{array}$ & $55(48.2)$ & Fibroepithelial polyp & $126(23.9)$ \\
\hline Malignant melanoma & $12(10.5)$ & $\begin{array}{l}\text { Epidermal inclusion } \\
\text { cyst }\end{array}$ & 84 (15.9) \\
\hline Adenocarcinoma & $10(8.8)$ & Inflammation & $72(13.7)$ \\
\hline $\begin{array}{l}\text { Invasive Paget's } \\
\text { disease }\end{array}$ & $8(7.0)$ & $\begin{array}{l}\text { Condyloma acumi- } \\
\text { nata }\end{array}$ & $52(9.9)$ \\
\hline Soft tissue tumors & $7(6.2)$ & Seborrheic keratosis & $26(4.9)$ \\
\hline Verrucous carcinoma & $5(4.4)$ & Nevus & $22(4.2)$ \\
\hline Basal cell carcinoma & $4(3.5)$ & $\begin{array}{l}\text { Hydradenoma } \\
\text { papilliferum }\end{array}$ & $17(3.2)$ \\
\hline $\begin{array}{l}\text { Neuroendocrine } \\
\text { tumors }\end{array}$ & $4(3.5)$ & Lichen sclerosus & $15(2.8)$ \\
\hline \multirow[t]{2}{*}{ Others } & $9(7.9)$ & Hyperkeratosis & $12(2.3)$ \\
\hline & & Lipoma & $10(1.9)$ \\
\hline Premalignant $(n=59)$ & & Others & $91(17.3)$ \\
\hline VIN1 & $20(33.9)$ & & \\
\hline VIN3 & $19(32.2)$ & & \\
\hline Paget's disease & $16(27.1)$ & & \\
\hline VIN2 & $4(6.8)$ & & \\
\hline
\end{tabular}


Table 2. Patient's demographic characteristics

\begin{tabular}{|c|c|c|c|c|}
\hline Demographic data & Benign $(n=527)$ & Premalignant $(n=59)$ & Malignant ( $n=114)$ & $P^{*}$ \\
\hline Age $($ mean $\pm S D)$ & $45.1 \pm 15.6$ & $52.9 \pm 14.5$ & $56.9 \pm 16.6$ & $<0.001^{* *}$ \\
\hline \multicolumn{5}{|l|}{ Parity (\%) } \\
\hline 0 & $192(36.4)$ & $13(22.1)$ & $21(18.4)$ & $<0.001^{* *}$ \\
\hline 1 & $159(30.2)$ & $14(23.7)$ & $17(14.9)$ & $0.002^{* *}$ \\
\hline 2 & $106(20.1)$ & $16(27.1)$ & $23(20.2)$ & 0.494 \\
\hline$>2$ & $70(13.3)$ & $16(27.1)$ & $53(46.5)$ & $<0.001^{* *}$ \\
\hline Postmenopause (\%) & $181(34.3)$ & $38(64.4)$ & $74(64.9)$ & $<0.001^{* *}$ \\
\hline \multicolumn{5}{|c|}{ Presenting symptom (\%) } \\
\hline Mass & $425(80.6)$ & $24(40.7)$ & $86(75.4)$ & $<0.001^{* *}$ \\
\hline Rash & $73(13.8)$ & $28(47.5)$ & $24(21.1)$ & $<0.001^{* *}$ \\
\hline Itching & $29(5.6)$ & $7(11.8)$ & $4(3.5)$ & 0.674 \\
\hline
\end{tabular}

*Benign vs Premalignant and malignant.

**Statistical significance $(P<0.05)$.

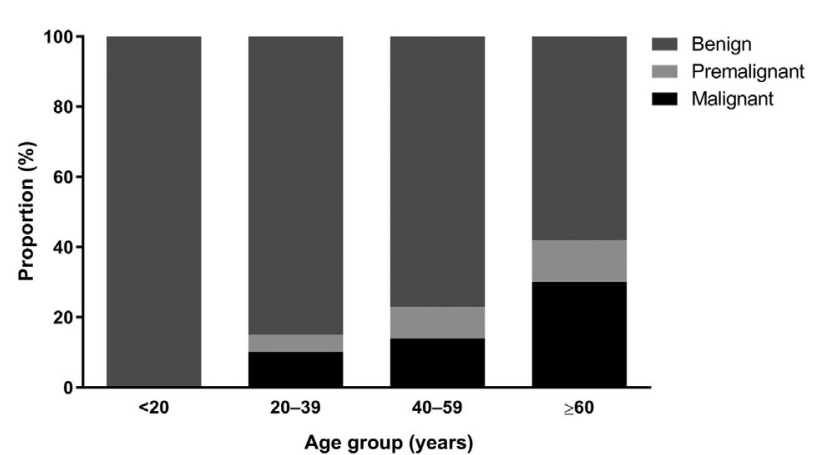

Figure 1. Proportion of premalignant and malignant lesions in each age group.

premalignant and malignant group, 64.7\% were menopause women. The most presenting symptom in benign and malignant groups was palpable mass that was seen in less than half of the premalignant group.

Figure 1 represented the proportion of premalignant and malignant lesions in each age group. As the age increased, the proportion of premalignant and malignant lesions also increased. After the six decades, there was $42.4 \%$ chance that the lesion was premalignant or malignant.

Proportion of premalignant and malignant lesions based on the menopausal status was shown in Figure 2. There was higher percentage of premalignant and malignant lesions in the menopause group $(38.2 \%$ vs $14.9 \%, P<0.001)$.

Parity is also a significant factor associated with the malignancy risk. Increased parity raised the probability of vulvar lesion being premalignant or malignant lesion with the highest peak in women with five and more children (Figure 3).

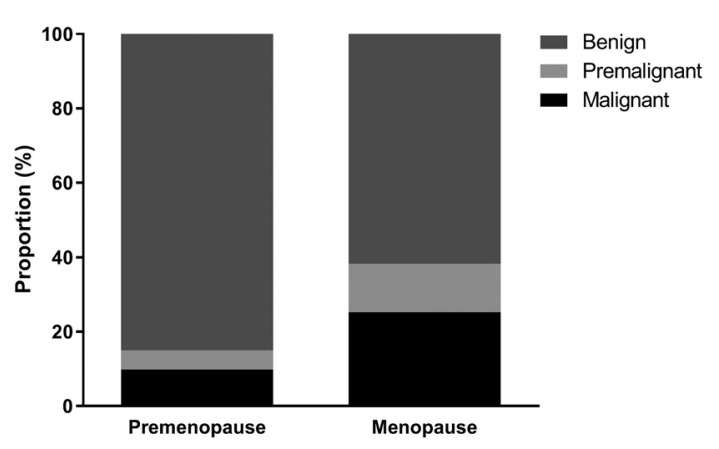

Figure 2. Proportion of premalignant and malignant lesions in premenopause and menopause group.

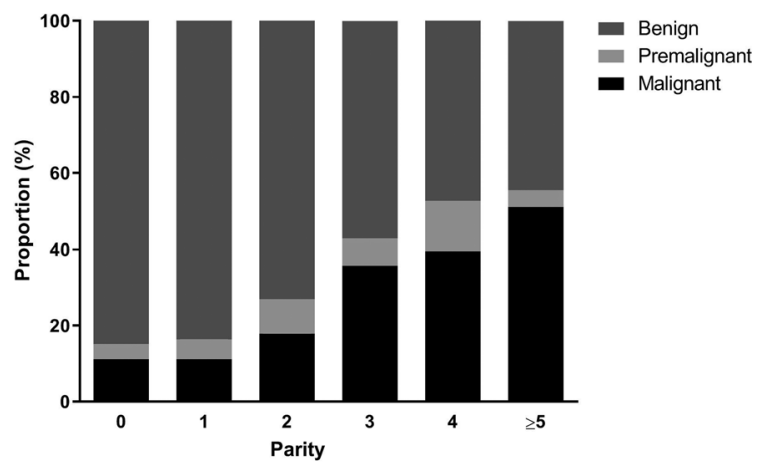

Figure 3. Proportion of premalignant and malignant lesions in different parity.

Lesion characteristics were shown in Table 3. Half of the lesions located at the labia majora. The malignant lesion is most commonly submitted from the labia majora. The benign lesion was significantly smaller than the premalignant and 
malignant lesion $(P<0.001)$. Majority of the lesions showed unchanged skin color, which accounted for $62.4 \%$.

Based on the location, if the lesion was located at the clitoris, it was more likely to be premalignant or malignant condition. However, if the lesion is located at Bartholin's gland, there was $94.7 \%$ chance that the lesion would be benign (Figure 4).

Proportion of premalignant and malignant lesions in each size of lesion was shown in Figure 5. There was more percentage that the lesion would be a premalignant or malignant condition with the larger size of lesion. If the lesion was larger than $4 \mathrm{~cm}$, the accumulate proportion of premalignant and malignant lesion was high as $73.4 \%$.
Figure 6 demonstrated the proportion of vulvar premalignant and malignant lesion in different lesion colors. Approximately one-third of hyperpigmented and hypopigmented lesions were premalignant or malignant condition, while the percentage was increasing to more than half if the lesion was erythematous.

The univariate and multivariate analyses were performed to determine the predicting factors of premalignant or malignant lesion (Table 4). In univariate analysis, there was statistical significance in old age, menopause, increased parity, large tumor size, lesion at clitoris, and erythematous lesion. Therefore, only four clinical factors remained significantly associated with

Table 3. Lesion characteristics

\begin{tabular}{|c|c|c|c|c|}
\hline Demographic data & Benign $(n=527)$ & Premalignant $(n=59)$ & Malignant $(n=114)$ & $P^{*}$ \\
\hline \multicolumn{5}{|l|}{ Location (\%) } \\
\hline Labia majora & $273(51.9)$ & $37(62.7)$ & $57(50.0)$ & 0.240 \\
\hline Labia minora & $122(23.1)$ & $10(16.9)$ & $24(21.1)$ & 0.523 \\
\hline Mon pubis & $47(8.9)$ & $3(5.1)$ & $9(7.8)$ & 0.558 \\
\hline Anterior fourchette & $30(5.7)$ & $6(10.2)$ & $6(5.3)$ & 0.365 \\
\hline Bartholin's gland & $36(6.8)$ & $0(0)$ & $2(1.8)$ & 0.015 \\
\hline Clitoris & $9(1.7)$ & $2(3.4)$ & $14(12.2)$ & $<0.001^{* *}$ \\
\hline Posterior fourchette & $10(1.9)$ & $1(1.7)$ & $2(1.8)$ & 0.990 \\
\hline \multicolumn{5}{|l|}{ Size $(\mathrm{cm})(\%)$} \\
\hline$\leq 2 \mathrm{~cm}$ & $434(82.4)$ & $21(35.6)$ & $23(20.2)$ & $<0.001^{* *}$ \\
\hline$>2-4 \mathrm{~cm}$ & $71(13.5)$ & $24(40.7)$ & $44(38.6)$ & $<0.001^{* *}$ \\
\hline$>4 \mathrm{~cm}$ & $22(4.1)$ & $14(23.4)$ & $47(41.2)$ & $<0.001^{* *}$ \\
\hline \multicolumn{5}{|l|}{ Color (\%) } \\
\hline Unchanged skin color & $364(69.1)$ & $44(74.6)$ & $29(25.4)$ & $<0.001^{* *}$ \\
\hline Hypopigment & $111(21.1)$ & $8(13.5)$ & $47(41.2)$ & $0.004^{* *}$ \\
\hline Erythematous & $26(4.9)$ & $7(11.9)$ & $28(24.6)$ & $<0.001^{* *}$ \\
\hline Hyperpigment & $26(4.9)$ & $0(0)$ & $10(8.8)$ & 0.662 \\
\hline
\end{tabular}

*Benign vs premalignant and malignant.

**Statistical significance $(P<0.05)$.

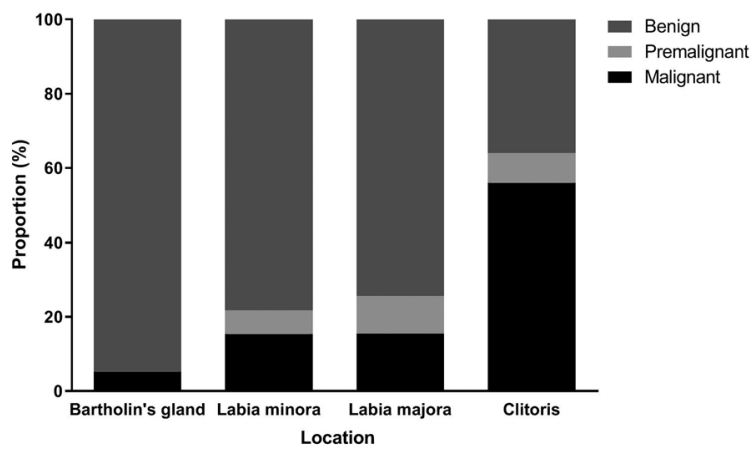

Figure 4. Proportion of premalignant and malignant lesions in each location.

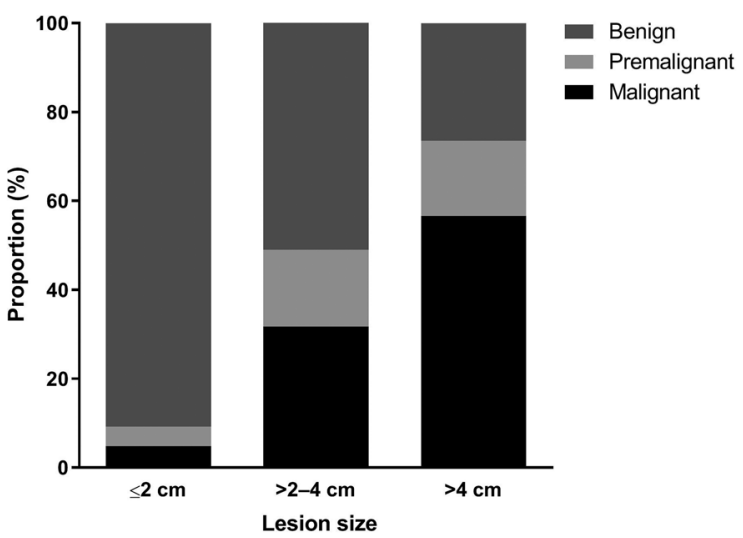

Figure 5. Proportion of premalignant and malignant lesions in different lesion size. 
malignancy risk by multivariate analysis. These four factors were increased parity (odds ratio [OR] 1.19, $P=0.010$ ), large tumor size (OR 2.00, $P<0.001$ ), lesion at clitoris (OR 16.67, $P=0.002$ ), and erythematous lesion (OR 2.41, $P=0.026$ ).

When divided into two 7-year periods, 2002-2008 and 2009-2015, there was increased in the incidence of both premalignant and malignant vulvar lesions, but statistical significance was demonstrated in only malignant group (Table 5).

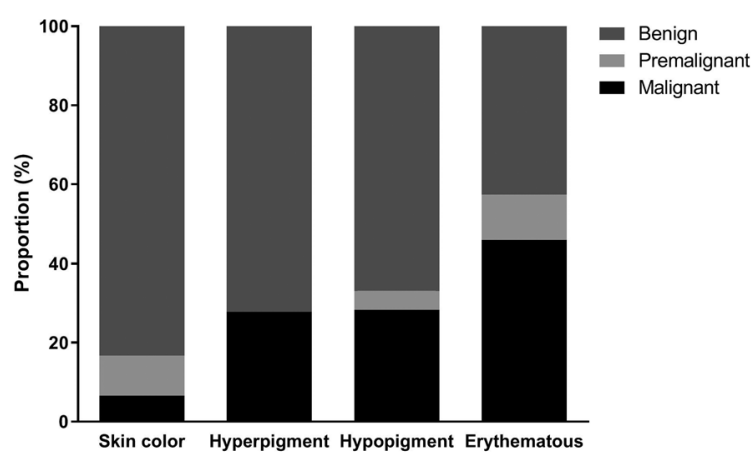

Figure 6. Proportion of premalignant and malignant lesions in different lesion colors.
As focusing on the women younger than 60 years; although the incidence of vulvar malignancy was increasing from $9.6 \%$ in $2002-2008$ to $14.5 \%$ in $2009-2015$, but there was no statistical significance $(P=0.083)$.

\section{Discussion}

Vulvar cancer is a rare disease and should be considered as a quietly progressive problem. The increased incidence has been reported in several countries such as Australia, England, Netherland, and Germany; especially in women younger than 60-70 years [4, 9-11]. Barlow et al. reported a significant $84 \%$ increase in incidence of vulvar cancer in women younger than 60 years with no change for women more than 60 years [9]. Trends of incidence of premalignant vulva lesion was also increased. It has been reported that vulvar carcinoma in situ increased $411 \%$ from 1973 to 2000 [5]. Invasive vulvar cancer increased $20 \%$ during the same period [5]. The present study of 14-year period showed that the authors also found the increased incidence of both premalignant and malignant vulvar

Table 4. Univariate and multivariate analysis to predict vulvar malignancy risk

\begin{tabular}{|c|c|c|c|c|c|c|}
\hline \multirow[t]{2}{*}{ Factors } & \multicolumn{3}{|c|}{ Univariate analysis } & \multicolumn{3}{|c|}{ Multivariate analysis } \\
\hline & OR & $95 \% \mathrm{Cl}$ & $P$ & OR & $95 \% \mathrm{Cl}$ & $P$ \\
\hline Age (years) & 1.04 & $1.03-1.05$ & $<0.001^{*}$ & 1.00 & $0.97-1.02$ & 0.890 \\
\hline Menopause (yes, no) & 3.51 & $2.45-5.03$ & $<0.001^{*}$ & 1.83 & $0.83-4.05$ & 0.130 \\
\hline Parity (times) & 1.41 & $1.28-1.56$ & $<0.001^{*}$ & 1.19 & $1.04-1.36$ & $0.010^{*}$ \\
\hline Size $(\mathrm{cm})$ & 2.10 & $1.84-2.40$ & $<0.001^{*}$ & 2.00 & $1.73-2.31$ & $<0.001^{*}$ \\
\hline \multicolumn{7}{|l|}{ Location } \\
\hline Labia majora & 6.19 & $1.46-26.23$ & $0.013^{*}$ & 3.26 & $0.72-14.7$ & 0.130 \\
\hline Labia minora & 5.02 & $1.14-21.89$ & $0.032^{*}$ & 4.20 & $0.91-19.6$ & 0.070 \\
\hline Clitoris & 32.00 & $6.19-165.2$ & $<0.001^{*}$ & 15.67 & $2.72-90.9$ & $0.002^{*}$ \\
\hline \multicolumn{7}{|l|}{ Color } \\
\hline Hyperpigment & 1.92 & $0.89-4.15$ & 0.098 & 2.38 & $0.94-6.06$ & 0.068 \\
\hline Hypopigment & 2.47 & $1.64-3.72$ & $<0.001^{*}$ & 1.14 & $0.68-1.91$ & 0.625 \\
\hline Erythematous & 6.71 & $3.81-11.83$ & $<0.001^{*}$ & 2.41 & $1.11-5.24$ & $0.026^{*}$ \\
\hline
\end{tabular}

*Statistical significance $(P<0.05)$.

$\mathrm{Cl}$, confidence interval; $\mathrm{OR}$, odds ratio.

Table 5. Trends of vulvar premalignant and malignant lesions

\begin{tabular}{lccc}
\hline & Year 2002-2008 $(\boldsymbol{n}=\mathbf{3 4 2})$ & Year 2009-2015 $(\boldsymbol{n}=\mathbf{3 5 8})$ & $\boldsymbol{P}$ \\
\hline Malignant vulvar lesion & $45(13.2 \%)$ & $69(19.3 \%)$ & $0.028^{*}$ \\
Premalignant vulvar lesion & $25(7.3 \%)$ & $34(9.5 \%)$ & 0.298 \\
\hline
\end{tabular}

*Statistical significance $(P<0.05)$. 
lesions, but statistical significance was demonstrated in only malignant group. Vulvar malignancy was significantly increased $6.1 \%$ from 2002-2008 to 2009-2015. However, there was not significantly increased incidence of vulvar cancer in the women younger than 60 years.

The present study was the largest one that recruited up to 114 cases of vulvar cancer, compared to other previous studies that was ranging from 26 to 69 cases [6-8]. The most common malignant vulvar lesion was squamous cell carcinoma, same as other studies. However, the proportion of squamous cell carcinoma was only $48.2 \%$, which was much lower than previous studies $(76 \%-89 \%)[1,2,4-8]$. This finding may be explained by the higher possibility to submit more different rare types of vulvar lesions than other hospital because $\mathrm{KCMH}$ is a tertiary referral center.

Based on the univariate and multivariate analyses, increased parity, large tumor size, clitoris-located lesion, and erythematous lesion were associated with increasing malignancy risk. One hypothesis of the pathogenesis of vulvar cancer is the exposure to the HPV [12]. Multiparous women seem to have higher risk of HPV infection and may associated with increased chance of developing vulvar cancer. Interestingly, lesion at the clitoris was associated with increased malignancy risk. This finding may be explained by the anatomy of the clitoris. The clitoris is located at the crevices between labia minora and is not easily seen or palpated. Small benign lesion may quietly regress without any symptom. The lesions that can be detected by the woman herself generally progress for a while, which are more commonly seen in the malignancy than in the benign condition.

Seven hundred cases of vulvar lesions in a 14-year period were reviewed, focusing on the pathological diagnosis and clinicopathologic features. Therefore, it had few limitations as it was a retrospective study. Biopsy or operation was not performed in every patient. Moreover, the operation was tended to be withheld in cases with benign-looking lesion. However, these data are still useful for patient counseling and can be used as the baseline data for further researches of the vulvar lesion.

\section{Conclusion}

The proportion of malignant and premalignant lesions in overall vulvar specimens was $16.3 \%$ and $8.4 \%$, respectively. Increased parity, large tumor size, clitoris-located lesion, and erythematous lesion were associated with increasing malignancy risk.

Author contributions. All the authors contributed substantially to the conception and design of this study. AT and PT contributed substantially to the acquisition of data. PT and RL analyzed and interpreted the data. PT drafted the manuscript. AT and RL contributed substantially to its critical revision. All the authors approved the final version submitted for publication and take responsibility for the statements made in the published article.

Acknowledgment. We did not receive any specific grant for this research from any funding agency in the public, commercial, or not-for-profit sectors.

Conflicts of interest statement. The authors have completed and submitted the ICMJE Uniform Disclosure Form for Potential Conflicts of Interest. None of the authors disclose any conflicts of interest.

\section{References}

[1] Léonard B, Kridelka F, Delbecque K, Goffin F, Demoulin S, Doyen J, et al. A clinical and pathological overview of vulvar condyloma acuminatum, intraepithelial neoplasia, and squamous cell carcinoma. Biomed Res Int. 2014; 201:480-573.

[2] Tcheung WJ, Selim MA, Herndon JE 2nd, Abernethy AP, Nelson KC. Clinicopathologic study of 85 cases of melanoma of the female genitalia. J Am Acad Dermatol. 2012; 67:598-605.

[3] Sankaranarayanan R, Ferlay J. Worldwide burden of gynaecological cancer: the size of the problem. Best Pract Res Clin Obstet Gynaecol. 2006; 20:207-25.

[4] Dittmer C, Katalinic A, Mundhenke C, Thill M, Fischer D. Epidemiology of vulvar and vaginal cancer in Germany. Arch Gyne col Obstet. 2011; 284:169-74.

[5] Judson PL, Habermann EB, Baxter NN, Durham SB, Virnig BA. Trends in the incidence of invasive and in situ vulvar carcinoma. Obstet Gynecol. 2006; 107:1018-22.

[6] Hanprasertpong J, Chichareon S, Wootipoom V, Buhachat R, Tocharoenvanich S, Geater A. Clinico-pathological profile of vulva cancer in southern Thailand: analysis of 66 cases. J Med Assoc Thai. 2005; 88:575-81.

[7] Pengsaa P, Pothinam S, Udomthavornsuk B. Vulvar carcinoma at Srinagarind Hospital, Khon Kaen, Thailand. Eur J Gynaecol Oncol. 1993; 14:56-62.

[8] Manchana T, Sirisubya N, Lertkhachonsuk R, Sittisomwong T, Vasuratna A, Termrungruanglert W, et al. Vulvar carcinoma at King Chulalongkorn Memorial Hospital between 1994-2003. Chula Med J. 2004; 48:91-9.

[9] Barlow EL, Kang YJ, Hacker NF, Canfell K. Changing trends in vulvar cancer incidence and mortality rates in Australia since 1982. Int J Gynecol Cancer. 2015; 25:1683-9.

[10] Lai J, Elleray R, Nordin A, Hirschowitz L, Rous B, Gildea C, et al. Vulvar cancer incidence, mortality and survival in England: age-related trends. BJOG. 2014; 121:728-38

[11] Schuurman MS, van den Einden LC, Massuger LF, Kiemeney LA, van der Aa MA, de Hullu JA. Trends in incidence and survival of Dutch women with vulvar squamous cell carcinoma. Eur J Cancer. 2013; 49:3872-80.

[12] Viens LJ, Henley SJ, Watson M, Markowitz LE, Thomas CC, Thompson TD, et al. Human papillomavirus-associated cancersUnited States, 2008-2012. MMWR Morb Mortal Wkly Rep. 2016; 65:661-6. 